\title{
Central Auditory and Vestibular Dysfunction Are Key Features of Autism Spectrum Disorder
}

\author{
Yusra Mansour ${ }^{1,2}$, Alyson Burchell ${ }^{2}$ and Randy J. Kulesza ${ }^{2 *}$ \\ ${ }^{1}$ Department of Otolaryngology, Henry Ford Macomb Hospital, Detroit, MI, United States, ${ }^{2}$ Department of Anatomy, Lake Erie \\ College of Osteopathic Medicine, Erie, PA, United States
}

Autism spectrum disorder (ASD) is a neurodevelopmental disorder characterized by repetitive behaviors, poor social skills, and difficulties with communication. Beyond these core signs and symptoms, the majority of subjects with ASD have some degree of auditory and vestibular dysfunction. Dysfunction in these sensory modalities is significant as normal cognitive development depends on an accurate representation of our environment. The hearing difficulties in ASD range from deafness to hypersensitivity and subjects with ASD have abnormal sound-evoked brainstem reflexes and brainstem auditory evoked potentials. Vestibular dysfunction in ASD includes postural instability, gait dysfunction, and impaired gaze. Untreated vestibular dysfunction in children can lead to delayed milestones such as sitting and walking and poor motor coordination later in life.

OPEN ACCESS

Edited by:

Srdjan Vlajkovic, The University of Auckland,

New Zealand

Reviewed by: Juliette Elizabeth Cheyne, The University of Auckland, New Zealand

Carly Demopoulos, University of California, San Francisco, United States

${ }^{*}$ Correspondence:

Randy J. Kulesza rkulesza@lecom.edu

Received: 18 July 2021 Accepted: 07 September 2021 Published: 29 September 2021

Citation:

Mansour Y, Burchell $A$ and Kulesza RJ (2021) Central Auditory and Vestibular Dysfunction Are Key Features of Autism Spectrum

Disorder.

Front. Integr. Neurosci. 15:743561. doi: 10.3389/fnint.2021.743561
Histopathological studies have revealed that subjects with ASD have significantly fewer neurons in the auditory hindbrain and surviving neurons are smaller and dysmorphic. These findings are consistent with auditory dysfunction. Further, the cerebellum was one of the first brain structures implicated in ASD and studies have revealed loss of Purkinje cells and the presence of ectopic neurons. Together, these studies suggest that normal auditory and vestibular function play major roles in the development of language and social abilities, and dysfunction in these systems may contribute to the core symptoms of ASD. Further, auditory and vestibular dysfunction in children may be overlooked or attributed to other neurodevelopmental disorders. Herein we review the literature on auditory and vestibular dysfunction in ASD. Based on these results we developed a brainstem model of central auditory and vestibular dysfunction in ASD and propose that simple, non-invasive but quantitative testing of hearing and vestibular function be added to newborn screening protocols.

Keywords: brainstem, hearing, vestibuar sytem, autism, screening tools

\begin{abstract}
Abbreviations: A1, primary auditory cortex; ABR, auditory brainstem response; AN, auditory nerve; ASD, autism spectrum disorder; ASR, acoustic stapedial reflex; BIC, binaural interaction components; CNIC, central nucleus of the inferior colliculus; CN, cochlear nuclei; DCN, dorsal cochlear nucleus; DNLL, dorsal nucleus of the lateral lemniscus; DPOAE, distortion product otoacoustic emission; IC, inferior colliculus; INLL, intermediate nucleus of the lateral lemniscus; ITD, interaural timing difference; LL, lateral lemniscus; LOC, lateral olivocochlear; LSO, lateral superior olive; MOC, medial olivocochlear; MSO, medial superior olive; NT, neurotypical; OAE, otoacoustic emission; SOC, superior olivary complex; SPON, superior paraolivary nucleus; Tz, trapezoid body; VCN, ventral cochlear nucleus; vMG, ventral nucleus of the medial geniculate; VNLL, ventral nucleus of the lateral lemniscus; VNTB, ventral nucleus of the trapezoid body; VOR, vestibulo-ocular reflex.
\end{abstract}




\section{INTRODUCTION}

\section{Autism Spectrum Disorder}

Autism spectrum disorder (ASD) is a developmental disability associated with impairment in social, communicative, and behavioral domains (CDC.gov, 2021). ASD affects approximately one in 54 children and is four times more common in males. While difficulties with hearing and balance are not diagnostic signs or symptoms, children or adults with a diagnosis of ASD may have difficulty hearing or attending to speech or vocalizations despite being able to hear other environmental sounds and they may have abnormal responses to sounds. Further, large scale studies suggest that most if not all individuals with ASD have some degree of auditory dysfunction (Greenspan and Wieder, 1997) and several studies indicate brainstem and cerebellar pathological changes in ASD (Ornitz, 1969; Bauman and Kemper, 1985; Courchesne et al., 1987, 1988, 1994a,b; Ogawa, 1989; Scott et al., 2009). Herein, we review auditory and vestibular dysfunction in ASD and propose the incorporation of these modalities into screening for ASD.

\section{The Auditory System}

The mammalian auditory system begins with bilaterally situated external ears or pinnae, that serve to collect and funnel sound pressure waves through the external auditory meatus towards the tympanic membrane. Vibrations of the tympanic membrane are transferred through the ossicles in the middle ear (tympanic cavity) to the oval window. Mechanical vibrations at the oval window transduce this energy to fluid waves of endolymph in the cochlear duct. These fluid waves activate mechanoreceptive inner hair cells in the organ of Corti in the cochlea. The central auditory pathway originates with bipolar neurons in the spiral ganglion. These neurons collect information from inner hair cells through their peripheral processes and relay this information via central axons to both the dorsal and ventral cochlear nuclei (DCN and VCN, respectively) in the rostral medulla (Figures 1A-C). Neurons in the VCN project bilaterally to the superior olivary complex (SOC; in the caudal pons) through the trapezoid body $(\mathrm{Tz})$ and the contralateral inferior colliculus (IC; midbrain) through the lateral lemniscus (LL; Figures 1A-C). The SOC is a collection of brainstem nuclei, and each nucleus contributes a unique circuit subserving a specific function. As a group, the SOC plays prominent roles in localization of sound sources, coding temporal and spectral features of sound, and descending modulation of the organ of Corti. Along the LL, there are ventral, intermediate, and dorsal nuclei of the lateral lemniscus (VNLL, INLL, and DNLL, respectively) that receive input from the VCN and SOC and project to the inferior colliculus (IC). The IC includes a central nucleus (CNIC), a dorsal cortex, and an external cortex. The CNIC forms an essential component of the ascending auditory pathway and sends a major projection to the medial geniculate in the thalamus and specifically the ventral nucleus of the medial geniculate (vMG). The vMG projects through the internal capsule to the primary auditory cortex (A1).

Humans have a comparatively narrow range of hearing sensitivity but are excellent low-frequency listeners. The SOC is subject to sometimes drastic interspecies variation but the core nuclei are modified to meet the specific hearing needs of the animal; accordingly, the human SOC is specialized for encoding and localizing lower frequency sounds and includes a prominent medial superior olive (MSO; Kulesza, 2007). The human MSO is composed of a thin column of neurons and each neuron forms both a medial and lateral dendrite (Kulesza, 2007; Mansour and Kulesza, 2021). Human MSO dendrites are symmetric and are distributed into the peri-MSO fields (Mansour and Kulesza, 2020, 2021). These dendrites serve to collect information from both ears: the lateral dendrite receives input from the ipsilateral ear and the medial dendrite receives input from the contralateral ear. Neurons of the MSO are often referred to as coincidence detector neurons since they function to encode differences in arrival time of sounds between the two ears-this is known as the interaural time difference (ITD). Therefore, the normal number and morphology of MSO neurons and their dendrites are required for normal ITD coding.

Along with the ascending auditory pathway described above, there is a descending pathway that begins in the cerebral cortex that includes neurons at each level of the pathway, and terminates in the cochlea (see Schofield, 2010 for a detailed review). This descending circuit is complex and integrates auditory and non-auditory inputs. The final neurons in this descending pathway are situated in the SOC and comprise two unique circuits: a medial olivocochlear system (MOC) and a lateral olivocochlear system (LOC). Neurons compromising the MOC reside mainly in the ventral nucleus of the trapezoid body (VNTB) and these neurons project to outer hair cells in the organ of Corti. This projection results in the contraction of outer hair cells, serving to reduce cochlear output to filter out background noises when listening in noisy environments. Neurons of the LOC are situated in and around the lateral superior olive (LSO). LOC neurons send axons to the ipsilateral cochlea and innervate auditory nerve axons that innervate inner hair cells. Together, olivocochlear neurons modulate the function of the cochlea to protect the cochlea from damage by loud sounds and for selective listening in background noise.

\section{The Vestibular System}

The mammalian vestibular system begins with delicate, endolymph-filled membranous labyrinths encased in each temporal bone (Lysakowski and Goldeberg, 2004). Each membranous labyrinth includes a cochlear duct, two enlarged sac-like structures-the utricle and saccule, and three semicircular canals (Figure 2). The utricle and saccule include collections of mechanoreceptive hair cells arranged in maculae (Lysakowski and Goldeberg, 2004). The stereocilia of the macular hair cells are embedded in an otolith membrane. Movements of the head (e.g., up and down) cause inertial movements of the otolith and mechanical activation of macular hair cells. This serves to encode linear motion and orientation of the head relative to gravity. The base of each semicircular canal includes an ampulla where it joins the utricle and each ampulla contains a crista ampullaris. The cristae are composed of mechanoreceptive hair cells with stereocilia embedded in a gelatinous matrix known as the cupula. Movements of 


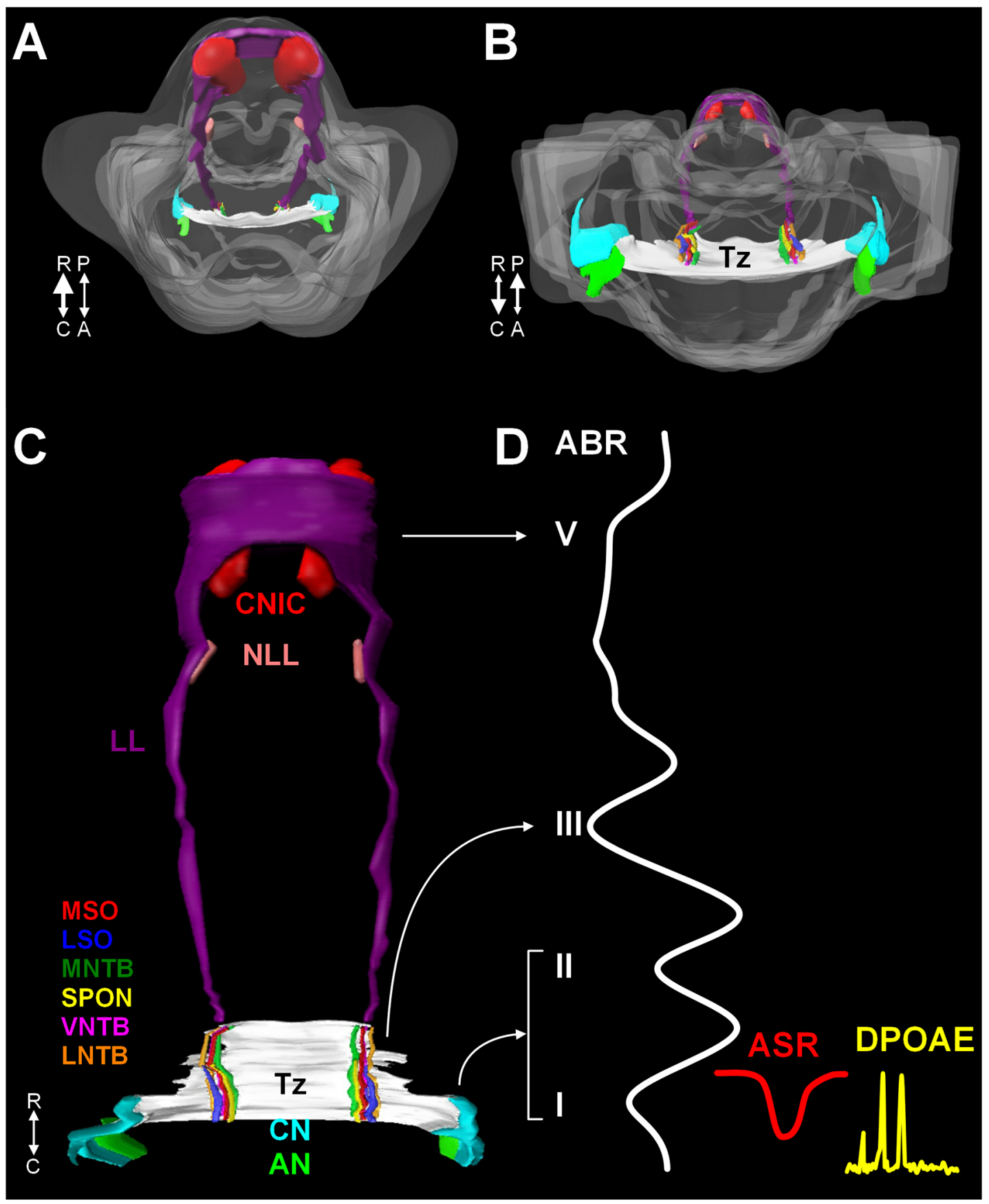

FIGURE 1 | A 3D reconstruction of the human auditory brainstem. Images (A) through (C) show 3D volume renderings of nuclei and tracts of the human auditory brainstem. Image (A) shows a rostral to caudal view (from midbrain down to the medulla) and (B) shows a caudal to rostral view (from medulla up to midbrain). Image (C) shows a posterior view (viewed from posterior to anterior). In (A) and (B), the contour of the brainstem is indicated in gray. A key to the colors and nuclei/tracts is shown in figure (C). The CN and SOC nuclei are limited to the rostral medulla and caudal pons. The LL extends from the caudal pons to the CNIC. Figure (D) shows examples of ABR, ASR, and distortion product DPOAE recordings juxtaposed to the levels of the auditory pathway they measure. Numbers in roman numerals indicate specific waves of the ABR. ABR waves I and II correspond to the AN and CN, wave III corresponds to the SOC. Waves IV and V correspond to the LL and CNIC respectively. Abbreviations: R, rostral; C, caudal; P, posterior; A, anterior; DPOAE, distortion product otoacoustic emission.

the cupula coincide with rotational movements of the head. Vestibular hair cells are innervated by peripheral processes of bipolar neurons located in the vestibular (Scarpa's) ganglion.
Neurons in the vestibular ganglion send central projections to the cerebellum and four vestibular nuclei residing along the floor of the fourth ventricle in the medulla and pons (Figure 2). The 


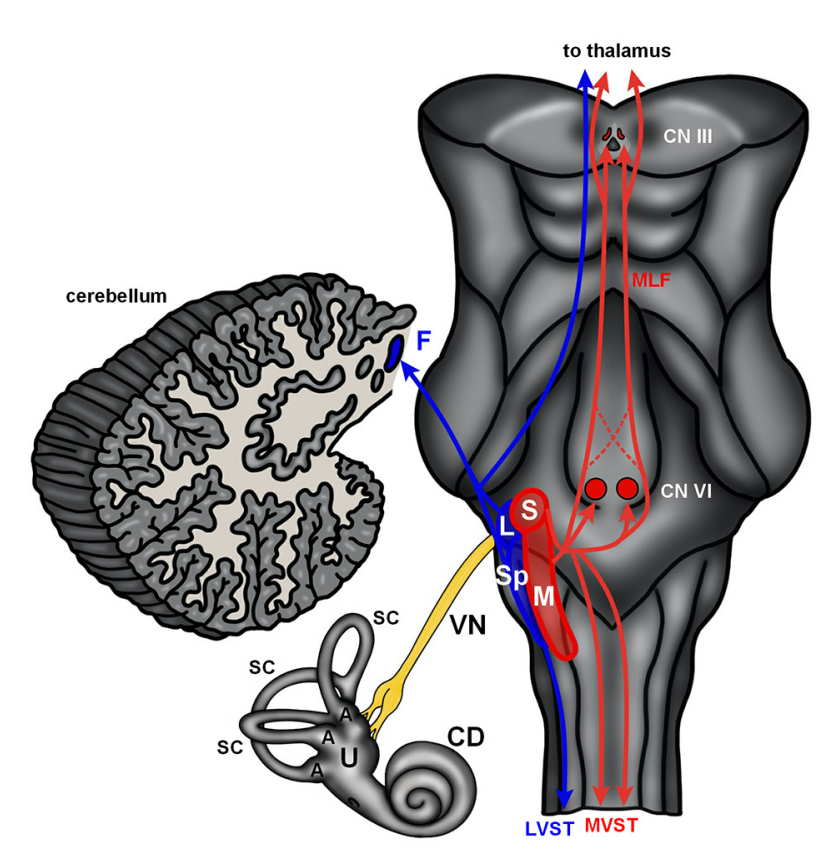

FIGURE 2 | The human vestibular brainstem. A schematic of the human vestibular pathway and vestibulocerebellum is shown. Vestibular hair cells are housed in cristae found in the ampulla (A) of the three semicircular canals (SC), and macula situated in both the utricle $(U)$ and saccule. These hair cell collections are innervated by the vestibular division of the vestibulocochlear nerve. The vestibular nerve (VN) projects to the vestibular nuclei (red and blue contours) that extend from the medulla into the caudal pons. The lateral $(\mathrm{L})$ and spinal (Sp) vestibular nuclei project to the fastigial nucleus (F) in the cerebellum and spinal cord via the lateral vestibulospinal tract (LVST). The superior (S) and medial (M) nucleus project to the spinal cord via the medial vestibular spinal tract (MVST) and nuclei controlling extraocular muscles (CN VI-abducens nucleus; CN III-oculomotor nucleus) via the medial longitudinal fasciculus (MLF). The vestibular nuclei also send projections to the thalamus. Abbreviations: $\mathrm{CD}$, cochlear duct.

superior and medial vestibular nuclei (Figure 2, red) receive their major inputs from the cristae and project along the medial vestibulospinal tracts and medial longitudinal fasciculus to nuclei controlling the extraocular muscles and to the cervical spinal cord to control gaze and maintain a stable platform for the eyes. The lateral vestibular nucleus (Deiters' nucleus) receives input from the cristae and macula and projects through the lateral vestibulospinal tract to influence postural reflexes (Figure 2, blue). The spinal (descending) nucleus receives input from the otolith organs and projects to the cerebellum, reticular formation, and spinal cord to regulate posture. Information from the vestibular ganglion and vestibular nuclei target the fastigial nucleus and flocculonodular lobe of the cerebellum (Figure 2, blue). Together, the vestibular apparatus and associated central connections encode movements of the head and direct adjustments to eye position, muscle tone, and body posture (Lysakowski and Goldeberg, 2004). Like the auditory hair cells, the vestibular sensory organs receive efferent innervation from cholinergic neurons near the genu of the facial nerve (Warr, 1975).

\section{Autism Spectrum Disorder and CN VIII Dysfunction}

\section{Auditory Dysfunction in ASD}

Autism spectrum disorder (ASD) is a neurodevelopmental disorder characterized by difficulties in social, communicative, and behavioral domains (CDC.gov, 2021). The most recent reports indicate that ASD impacts one in 54 children with a strong predilection for males (CDC.gov, 2021). One of the key signs/symptoms of ASD is abnormal responses to sensory stimuli. This can manifest as hypersensitivity or overreactions involving somatic sensations (touch) or special senses (smell, vision, and hearing). Beyond abnormal responses to sound, auditory dysfunction is present in most, if not all individuals with ASD (Greenspan and Wieder, 1997; Tomchek and Dunn, 2007; Bolton et al., 2012). This dysfunction ranges from deafness to hyperacusis and often includes difficulty listening to background noise and understanding speech (Roper et al., 2003; Alcántara et al., 2004; Khalfa et al., 2004; Szelag et al., 2004; Teder-Sälejärvi et al., 2005; Gravel et al., 2006; Tharpe et al., 2006; Russo et al., 2009). Collet et al. (1993) were the first to suggest the hyperacusis observed in ASD might be related to abnormalities in the MOC system. Consistent with these reports, hearing difficulties have been proposed as a cardinal indicator of ASD (Osterling and Dawson, 1994).

Interestingly, involvement of the auditory system in ASD was suspected in the original report of autistic children in 1943. One of the common findings in these children was difficulty with language and hypersensitivity to loud noises (Kanner, 1943). Observations from a study of auditory-evoked potentials further supported the idea of auditory involvement (Ornitz et al., 1968). Additional studies of individuals with ASD implicated problems with processing language (Hermelin and Frith, 1971), focusing on multiple sounds or stimuli (Reynolds et al., 1974), conductive hearing loss (Smith et al., 1988) and hyposensitivity, or hypersensitivity depending on the stimulus modality (Ornitz et al., 1968; Hayes and Gordon, 1977; Rosenhall et al., 1999). A number of studies also suggested difficulties in processing complex sounds such as speech. Specifically, (Koegel and Schreibman, 1976) reported on a child with ASD who appeared to be deaf for complex sounds (white noise) but responded to environmental sounds at normal thresholds. A review of 1st birthday home videos revealed that children with ASD often failed to orient to their name being called (Osterling and Dawson, 1994), have a clear preference for noise or non-verbal sounds over speech and vocalizations (Klin, 1991, 1993) or frank impairment for speech sounds (Ceponiene et al., 2003; Jeste and Nelson, 2009; Bidet-Caulet et al., 2017; Jayanath and Ozonoff, 2020).

The auditory dysfunction in ASD has been studied and characterized by numerous researchers using fairly simple, non-invasive techniques. The acoustic stapedial reflex (ASR) has been utilized to examine the function of the lower auditory brainstem, facial nucleus, and contraction of the stapedius muscle in subjects with ASD with some conflicting results (Figure 1D; Gravel et al., 2006; Tharpe et al., 2006; Gomes et al., 2008). Specifically, only Gomes found that subjects with ASD 
had lower thresholds relative to neurotypical (NT) individuals. (Gravel et al., 2006) found no significant differences between control children and subjects with ASD in cohorts that were matched by age and hearing threshold. We examined the ASR in a group of 29 neurotypical children (ages 7-17 years) and 54 children and young adults with high-functioning ASD (ages 4-23 years; Lukose et al., 2013). The subjects with ASD had significantly lower thresholds (i.e., hypersensitivity), and significantly longer response latencies. The longer latencies were most commonly observed in response to a $1 \mathrm{kHz}$ tone presented in the ipsilateral ear. In all NT subjects, ipsilateral reflex responses always occurred at shorter latencies compared to contralateral reflex responses regardless of tone frequency. However, in subjects with ASD, this clear and predictable pattern of slower ipsilateral responses was not always found. Specifically, when we stimulated the left ear of subjects with ASD, the ipsilateral reflex responses occurred at a significantly longer latency compared to the contralateral response. Finally, in our study of the ASR, $97 \%$ of subjects with ASD had at least one response outside the $95 \%$ confidence interval of NT responses. Regardless, our results are based on a relatively small group of children and young adults-whether these findings can be generally extended to subjects with ASD will require further investigation.

The ABR is a sound-evoked response of synchronized brain activity and each peak or wave corresponds to a particular level of the auditory brainstem pathway (Figure 1D). The ABR has provided the most insight into the function of brainstem centers in ASD. The majority of studies of the ABR in subjects with ASD over the past 40 years provide evidence that subjects with ASD have smaller amplitudes in waves I, II, III, IV, and V (Ornitz et al., 1972; Gillberg et al., 1983; Martineau et al., 1987, 1992; Klin, 1993), longer latencies between waves I-III and waves I-V (Taylor et al., 1982), and longer latencies/slower responses (Ornitz, 1969; Student and Sohmer, 1978; Rosenblum et al., 1980; Sohmer, 1982; Tanguay et al., 1982; Gillberg et al., 1983; Sersen et al., 1990; Thivierge et al., 1990; Wong and Wong, 1991; Maziade et al., 2000; Kwon et al., 2007; Roth et al., 2012; Azouz et al., 2014; Taş et al., 2017; Miron et al., 2018, 2021; Ramezani et al., 2019; Delgado et al., 2021; reviewed in Talge et al., 2018). These longer latency and lower amplitude responses have been attributed to the immaturity of brainstem circuits (Li et al., 2020). A recent study showed delays in speech-based ABRs (Chen et al., 2019) and reduced binaural interaction components (BIC) of the ABR in subjects with ASD (ElMoazen et al., 2020). The latter study also found a significant positive correlation between the amplitude of the BIC ABR waveform and both language and social scores in subjects with ASD (ElMoazen et al., 2020).

The literature provides convincing evidence that $\mathrm{ABRs}$ can be used as a screening instrument for the risk of ASD and/or other neurodevelopmental disorders. Specifically, a prospective study of ABRs found that young children (birth to 3 months) with longer wave $\mathrm{V}$ latencies and $\mathrm{I}-\mathrm{V}$ interpeak latencies were later diagnosed with ASD (Miron et al., 2016). Consistent with observed asymmetries in ASR and otoacoustic emissions (OAEs; see below), these authors found longer III-V interpeak latencies when stimulating the right ear only. In fact, these changes in wave $\mathrm{V}$ have a positive predictive value of $78 \%$ and a negative predictive value of $73 \%$ for wave $\mathrm{V}$. These differences in subjects with ASD can be further illustrated with masking experiments. Such paradigms revealed abnormal interpeak latencies between waves I-V and III-V (Thivierge et al., 1990), the reduced amplitude of wave III (Källstrand et al., 2010), and asymmetric masking by contralateral noise (Khalfa et al., 2001).

While ASR and ABRs examine brainstem circuits, the function of the cochlea can be evaluated using otoacoustic emissions (OAEs). Similar to the asymmetry seen in ASR testing, subjects with ASD exhibited abnormal OAEs with marked asymmetry (Khalfa et al., 2001) and significantly reduced responses in the $1 \mathrm{kHz}$ ranges (Bennetto et al., 2017). However, other researchers have found hypersensitivity or elevated responses (Danesh and Kaf, 2012; Taş et al., 2017). These conflicting results might be attributed to differences in subjects, equipment, and/or interpretation of the data. Also, the direct involvement of the cochlea in ASD is unclear. While OAEs provide an objective measure of the auditory function, its value as a screening tool is unclear. Beyond differences in ASR, OAEs, and ABRs, there is abundant evidence for additional problems in auditory processing in ASD. Specifically, subjects with ASD have difficulties with temporal processing (Russo et al., 2008; Bhatara et al., 2013; Foss-Feig et al., 2017), difficulties listening in the presence of background noise (Alcántara et al., 2004; TederSälejärvi et al., 2005) and problems with sound localization tasks (Osterling and Dawson, 1994; Baranek, 1999; Werner et al., 2000; Dawson et al., 2004; Lodhia et al., 2014, 2018). Finally, there are reports of dysfunction in the auditory forebrain. This includes weaker interhemispheric projections, stronger projections from the thalamus to the cortex in subjects with ASD (Linke et al., 2018), and right-left asymmetries of the secondary auditory cortex (Orekhova et al., 2012; Azouz et al., 2014). Additionally, there is evidence for abnormalities in cortical evoked auditory potentials (reviewed in O'Connor, 2012). It is unclear if these forebrain abnormalities result from dysfunction of brainstem centers or if the auditory forebrain is an additional primary site of injury in ASD. Therefore, it seems very likely that the difficulties children with ASD have developing language is intimately related to problems encoding and understanding the complex temporal and spectral features of speech.

Taken together, these studies implicate the lower auditory brainstem as a key site, if not the origin of abnormal circuitry and dysfunction in ASD. These changes can be identified in young children and can be assessed at birth. It is important to recognize that identification of these differences requires careful analysis of the responses. Newborn hearing screenings are often superficial and many children with auditory dysfunction pass these newborn screens or are missed on follow-up testing. In fact, a recent study demonstrates that childred who failed newborn ABR screens but were diagnosed with normal hearing at follow-up were five to 10 times more likely to be diagnosed with ASD (Tu et al., 2020). We hypothesize the majority of children that will be diagnosed with ASD have these hearing issues at birth and are missed by routine newborn screening because they have clinically normal hearing thresholds. Consistent with this hypothesis, only a small number of children with ASD have 
abnormal pure tone audiometry results, but when combined with comprehensive auditory screening (including audiometry, tympanometry, acoustic reflexes, OAE, and ABR) more than half of the subjects have an abnormal result; regardless subjects with ASD who pass these screens can still have difficulty with speech and language tasks (Demopoulos and Lewine, 2016).

\section{Auditory Brainstem Dysmorphology in ASD}

A number of imaging studies revealed smaller cerebella and brainstems in subjects with ASD (Courchesne et al., 1988, 1994a,b; Gaffney et al., 1988; Murakami et al., 1989; Ciesielski et al., 1990; Hashimoto et al., 1992, 1993, 1995; Kleiman et al., 1992; Piven et al., 1992). Postmortem neuropathological studies confirmed that subjects with ASD have consistent dysmorphology in the brainstem and cerebellum (Williams et al., 1980; Bauman and Kemper, 1985; Bauman, 1991; Ritvo et al., 1986; Arin et al., 1991; Rodier et al., 1996; Bailey et al., 1998; Kulesza and Mangunay, 2008; Kulesza et al., 2011; Lukose et al., 2015; Mansour and Kulesza, 2020). Specifically, these studies revealed fewer cerebellar Purkinje cells and hypoplasia of the facial nucleus and SOC. Further investigations by Wegiel and coworkers revealed multifocal heterotopias and dysplasias in the forebrain and cerebellum and significantly fewer cerebellar Purkinje cells (Wegiel et al., 2010, 2014). Together, these findings support multiple sites of impaired neurogenesis, neuronal migration, and/or neuron survival in ASD (Wegiel et al., 2010, 2014).

Some of the first evidence for focal brainstem deficits in ASD was the work of Rodier and colleagues (Rodier et al., 1996). These researchers found significant hypoplasia of the facial nucleus and SOC, abnormal bundles of axons related to the hypoglossal nucleus, and significant reduction in the rostrocaudal length of the pons. Based on their finding of changes in the SOC, together with reports of gross brainstem dysmorphology and hearing difficulties in ASD, we hypothesized these hearing difficulties are directly related to dysmorphology of lower auditory brainstem centers. We investigated this hypothesis first by studying the brainstems of five subjects with ASD (8-32 years of age) and two typical developing controls (26-29 years of age; Kulesza and Mangunay, 2008). A preliminary study of these specimens revealed noticeable changes in the MSO and we, therefore, focused our analysis on this nucleus. Our previous study of over 85 brainstems from NT subjects revealed the human MSO is composed of a thin column of 13-14,000 neurons (Kulesza, 2007; Lukose et al., 2015; Mansour and Kulesza, 2021) each emitting medial and lateral dendrites collecting input from the contralateral and ipsilateral ears, respectively (Mansour and Kulesza, 2021). The structure and arrangement of MSO neurons is essential to their function of encoding ITDs. We discovered that the MSO from subjects with ASD have significantly smaller neurons and the majority of these neurons have round/oval soma. We also found these neurons are abnormally oriented within the MSO. We then studied a larger cohort of brainstems, from nine subjects with ASD (2-36 years of age) and four NT individuals (4-32 years of age; Kulesza et al., 2011). In this study we analyzed all six SOC nuclei and found fewer and significantly smaller neurons in five of the six constituent nuclei; only the VNTB was unaffected (Lukose et al., 2011). Subjects with ASD also had extracellular eosinophilic fibers, hypergliosis around the MSO, and in two subjects (two of nine; $22 \%$ ) clusters of ectopic neurons in the pontine tegmentum. We then extended this to an even larger cohort including 10 NT subjects (3-32 years of age), 16 subjects with ASD (5-56 years of age) and 12 subjects with ASD and a duplication of the $q$ region of chromosome 15 [dup(15q)] (5-39 years of age; Lukose et al., 2015). In this cohort, we found fewer and smaller neurons in all SOC nuclei except the VNTB. Consistent with our previous studies, the MSO was the most severely affected nucleus in the SOC. In NT subjects, the MSO included about 13,000 neurons. In subjects with $\mathrm{ASD}$ or $\mathrm{ASD}+\operatorname{dup}(15 \mathrm{q})$, there were only about 5,400 neurons in the MSO and these neurons were significantly smaller, more round, and abnormally arranged in the nucleus. The peri-MSO was also significantly smaller in subjects with ASD (Mansour and Kulesza, 2020) and we interpret this finding to suggest that dendrites of MSO neurons are significantly shorter and less complex than NT subjects. Consistent with this hypothesis, human MSO neurons from subjects with ASD are smaller, more circular, and emit smaller caliber primary dendrites (Kulesza et al., 2011; Lukose et al., 2015). In this cohort, we compared the total number of MSO neurons with the subject's Autism Diagnostic Interview-Revised (combined social, communication, and behaviors scores); however, there was no relationship between these values. Our previous studies of the human MSO from NT subjects revealed round/oval neurons are more common in younger subjects ( $<10$ years of age). Therefore, we interpret the presence of round/oval neurons in the adult MSO of subjects with ASD to indicate brainstem immaturity or arrested development. In this study, we also found ectopic clusters of neurons in the caudal pontine tegmentum. We believe these ectopic cells to be neurons lost during migration-neurons possibly destined for the SOC that never arrived and therefore fail to participate in auditory circuits. Recently, we constructed $3 \mathrm{D}$ volumetric models of the human SOC nuclei from young neurotypical subjects and subjects with ASD (Mansour and Kulesza, 2020). Consistent with our previous studies, we found that in ASD, all of the SOC nuclei except the VNTB occupy smaller volumes and this was not related to overall brain size. Our findings of severe dysmorphology and neuronal loss in the MSO of subjects as young as 2 years old and the observation of Purkinje cell loss with an intact inferior olive are consistent with developmental dysfunction before 28-30 weeks of gestation (Bauman and Kemper, 2005). Further, we propose that deficits in higher degree auditory function result from abnormal coding of temporal and spectral features by the cochlear nuclei $(\mathrm{CN})$ and SOC. Based on our consistent observations of dysmorphology, we propose the MSO be added to the claustrum and cerebellar Purkinje cells as neuropathological hallmarks of ASD (Wegiel et al., 2014).

\section{Modified Auditory Brainstem Circuitry in ASD}

It is important to note that ASD is a spectrum disorder and not all individuals are affected to the same degree. Indeed, our morphological studies show not all subjects have the same degree of hypoplasia, the number of ectopic neurons, 
or gliosis. We attribute hyposensitivity to sound to result from fewer neurons, smaller axons, and abnormal ascending projections to the CNIC. These changes undoubtedly contribute to changes in the ABR and ASR, problems with vocalizations and localization of sound sources and likely contribute extensively to dysfunction of the auditory forebrain. We believe that hypersensitivity and difficulty listening in background noise likely result from changes in the number of SOC or facial nucleus neurons, and/or their connectivity or alterations in the organ of Corti.

We have recently demonstrated that human MSO neurons form symmetric medial and lateral dendrites, that glycinergic inputs are segregated to the cell body and proximal dendrites while excitatory inputs are arranged further distally (Mansour and Kulesza, 2021). These features are crucial for normal MSO function. In subjects with ASD, not only are there fewer MSO neurons but these neurons are smaller, their dendrites are significantly shorter and issued in almost random directions (Figure 3). We believe that in ASD, the reduction in the size of dendrites results in less area for collecting and integrating inputs from the ipsilateral and contralateral ears, and the random arrangement likely results in a poorly organized tonotopic map in the MSO (Figure 3). As a result, MSO neurons are not able to precisely extract timing and spectral information from their binaural inputs. Furthermore, there is a significant reduction in the number of MSO neurons and likely reduced projection from the MSO and SOC. Together, these findings suggest that not only is there a significant reduction in the MSO and SOC projection to the CNIC, but also this input is not carrying the same type/quality of information about the auditory environment. We proposed that the changes observed by many researchers in ABRs can be attributed to the reduced number of brainstem neurons, smaller, poorly myelinated axons, and/or abnormal patterns of activation in the auditory nerve (AN), Tz, LL. Accordingly, we believe that subjects with ASD fail to encode many complex features of vocalizations and may miss subtle features and auditory cues.

The VNTB functions in multiple aspects of hearing including descending modulation of the cochlea and fine-tuning local and ascending circuits. In subjects with ASD, we have found no changes in size or number of VNTB neurons or volume occupied by this nucleus. The descending projection from the VNTB to the cochlea has an identified role in filtering sound necessary for listening in background noise. However, subjects with ASD have difficulties listening to background noise. We have yet to assess the connectivity of the VNTB in human subjects. But we have examined projections of the VNTB in an animal model of ASD and found no differences from control animals (this issue, Mansour and Kulesza, 2021). However, in human subjects, it is unclear if VNTB projections are intact and/or have normal function. A recent study showed abnormal OAEs in subjects with ASD (Bennetto et al., 2017) implicating dysfunction of the organ of Corti. Morphological studies of the cochlea, including afferent and efferent innervation, from subjects with ASD, will clarify the structural and functional roles of the sensory receptors in this condition.

\section{Vestibular and Cerebellar Issues in ASD}

A number of early morphological studies of subjects with ASD suggested the brainstem as the origin of dysfunction (Ornitz, 1969; Ogawa, 1989). Some of the first support for this hypothesis was provided by imaging studies revealing changes in the cerebellum (Bauman and Kemper, 1985; Courchesne et al., 1987, 1988, 1994a,b; Scott et al., 2009). Specifically, these studies found hypoplasia of the cerebellar vermis involving lobules VI and VII and more widespread involvement of the vermis including lobules I-V and VIII-X (Courchesne et al., 1994a,b; Levitt et al., 1999). Consistent with these imaging studies, microscopic

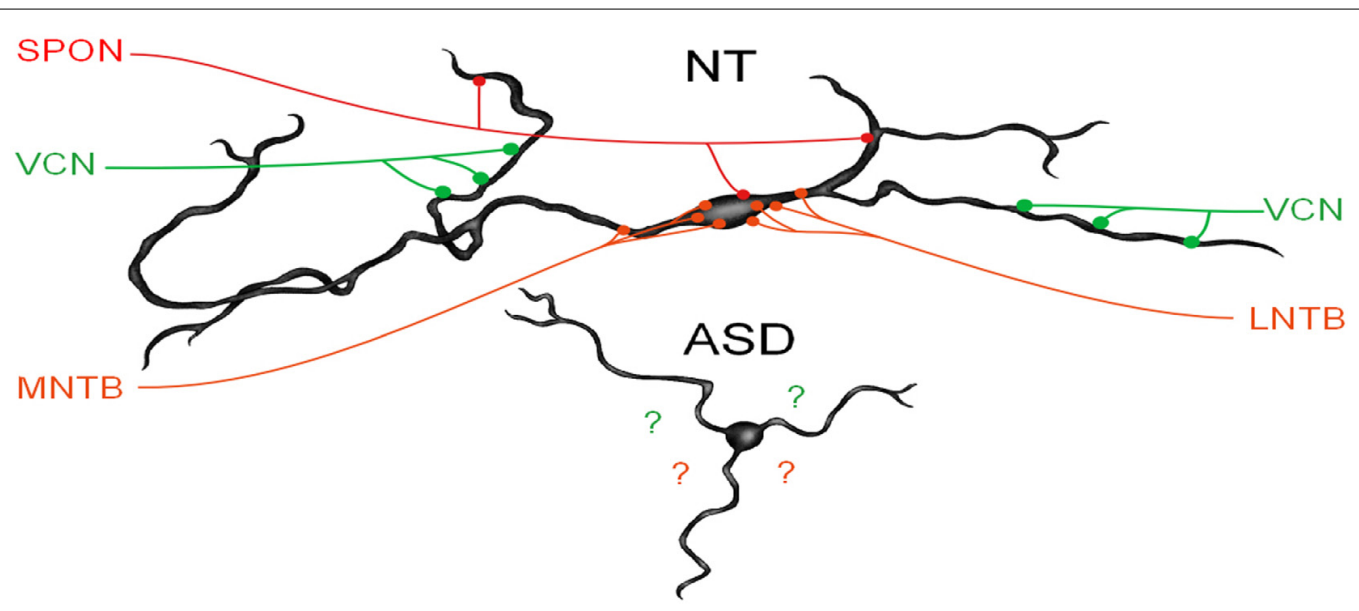

FIGURE 3 | MSO dysmorphology in ASD. The top image shows a reconstruction of a human MSO neuron (Mansour and Kulesza, 2021). Human MSO neurons have slender cell bodies that form symmetric dendrites on both the medial and lateral sides of the MSO cell column. MSO neurons receive symmetric glutamatergic input from both ipsilateral and contralateral VCN and these are distributed symmetrically on distal dendrites, glycinergic inputs are distributed primarily on the cell body and proximal dendrites and originate from the medial and lateral nuclei of the trapezoid body (MNTB and LNTB, respectively). Additionally, there are GABAergic inputs from the superior paraolivary nucleus (SPON). MSO neurons integrate these precisely arranged and timed inputs to extract spectral and temporal features of sound. MSO neurons in subjects with ASD lack the same morphology and distribution and the arrangement of these inputs are unknown. 
studies of the cerebellum revealed variable changes in the size of cerebellar Purkinje cells, with fewer Purkinje cells in the posterior cerebellum and occasionally the vermis and fewer neurons in the deep cerebellar nuclei in ASD (Bauman et al., 1995; Bauman, 1996). However, other studies have shown no difference in cerebellum size/volume between subjects with ASD and NT subjects (Scott et al., 2009). These conflicting results in cerebellum morphology might be attributed to variations amongst study subjects, ASD severity, or diagnoses. Indeed, detailed and systematic studies of the cerebellum and brainstem are needed to fully appreciate how these brain regions are impacted in ASD.

While motor signs and symptoms are not diagnostic features of ASD, deficits in motor skills and coordination are receiving more attention (Gernsbacher et al., 2008; Bhat et al., 2012; Lai et al., 2014; Sacrey et al., 2014). Further, several studies have demonstrated dysfunction of the vestibular system and/or vestibular circuits in the cerebellum. A number of early studies indicated that subjects with ASD have postural issues, problems with balance (Ritvo et al., 1969; Ornitz, 1970; Molloy et al., 2003; Smoot Reinert et al., 2015), and abnormal responses to vestibular stimulation (Slavik et al., 1984). Specifically, after rotational stimulation subjects with ASD had a slower onset of the primary nystagmus response and fewer beats during the secondary response (Ornitz et al., 1985). Subjects with ASD have irregular patterns of horizontal gaze, abnormal rotationinduced vestibulo-ocular reflexes (VOR), and VOR-based tasks that were attributed to abnormal cerebellum and brainstem circuitry (Carson et al., 2017; Caldani et al., 2020). VOR has been proposed to serve some diagnostic value in ASD (Thabet, 2014). Young subjects with ASD have longer latency saccades compared to age-matched neurotypical controls (Furman et al., 2015). In a recent population-based study of over 10 million neurotypical and 61,000 children with ASD, it was found that ophthalmic dysfunction was far more common in children with ASD (Chang et al., 2021). Specifically, ophthalmic dysfunction was present in $\sim 14 \%$ of children with ASD, that strabismus was four times more common, and nystagmus was nearly 10 times more common in ASD. Interestingly, in a study of 62 subjects with ASD, end-stage nystagmus was associated with better performance on language, cognitive and motor screens (Pineda et al., 2015). Vestibular involvement in ASD is not as clear as auditory issues - in a study of 79 subjects with ASD ranging in age from 5-52 years of age there was no difference in responses to rotational stimulation (Furman et al., 2015) and in a study of 13 children with ASD there was no difference in post-rotary nystagmus (Goldberg et al., 2000). But, children with ASD have abnormal postural responses after vestibular stimulation (Smoot Reinert et al., 2015). Vestibular issues are likely under-reported in children with ASD and may go unrecognized. This is significant as unidentified, or untreated vestibular issues in childhood can have a number of poor outcomes. In particular, normal vestibular function is required for normal posture and gaze, development of fine motor skills, proper cognitive development and educational performance, and emotional and social behavior (reviewed in Van Hecke et al., 2019). The cerebellum also receives input from a number of non-motor/somatosensory sources and projects widely over the neuroaxis. Consistent with these projections, there is evidence that the cerebellum is involved in multiple functions beyond motor coordination via projections to the hippocampus, amygdala, and septal nuclei (Heath, 1973; Heath and Harper, 1974).

\section{SUMMARY AND CONCLUSIONS}

The literature provides abundant evidence for both structural and functional hearing deficits in ASD. These findings are consistent with key signs and symptoms, specifically that individuals with ASD appear unaware when people talk to them, but respond to non-verbal sounds, repeat words or phrases in place of normal speech and have abnormal reactions to sensory stimulation (CDC.gov, 2021). Importantly, both functional and anatomical investigations indicate these auditory problems are present at birth. Consistent with these findings, we propose that qualitative ABRs or ASRs be used to screen for ASD risk (Lukose et al., 2013; Mansour and Kulesza, 2020; in accordance with other researchers: Grewe et al., 1994). Observations of spontaneous nystagmus and testing of VORs are also simple and non-invasive. The literature also provides evidence for vestibular dysfunction in children diagnosed with ASD. Similarly, if these vestibular issues can be identified in the early postnatal period, they could lead to early diagnosis of ASD and/or raise suspicion for other neurodevelopmental conditions. The addition of vestibular assessment to a neonatal auditory testing panel, we believe, would only improve the diagnostic power of early screening. Accordingly, future research in this area should be centered on determining the predictive value of combined auditory and vestibular testing on newborns for diagnosis of ASD and/or other neurodevelopmental disorders. Currently, almost all US states require newborn hearing screening ${ }^{1}$, although these tests are considered only on a pass/fail basis. We propose these initial screenings be evaluated on a quantitative basis to better stratify the risk of an ASD diagnosis. The addition of simple, noninvasive vestibular screening will only increase the value of auditory and vestibular assessment. Of course, the goal of early detection and diagnosis of ASD is early intervention to improve the quality of life and ensure the best possible outcomes and social/academic integration. There is evidence that early intervention for children with ASD focusing on eye contact, gesturing, and vocalizations results in significant improvements in the child's language and social interactions (Wong and Kwan, 2010).

\section{AUTHOR CONTRIBUTIONS}

YM: literature review, made figures, and revised the manuscript. $\mathrm{AB}$ : literature review and revised manuscript. RK: literature review, wrote draft, made figures, and revised the manuscript. All authors contributed to the article and approved the submitted version.

\footnotetext{
$\overline{{ }^{1} \text { CDC.gov/ncbddd/hearingloss/screening.html }}$
} 


\section{REFERENCES}

Alcántara, J. I., Weisblatt, E. J., Moore, B. C., and Bolton, P. F. (2004). Speechin noise perception in high-functioning individuals with autism or Asperger's syndrome. J. Child Psychol. Psychiatry 45, 1107-1114. doi: 10.1111/j.1469-7610. 2004.t01-1-00303.x

Arin, D. M., Bauman, M. L., and Kemper, T. L. (1991). The distribution of Purkinje cell loss in the cerebellum in autism. Neurology 41:307.

Azouz, H. G., Kozou, H., Khalil, M., Abdou, R. M., and Sakr, M. (2014). The correlation between central auditory processing in autistic children and their language processing abilities. Int. J. Pediatr. Otorhinolaryngol. 78, 2297-2300. doi: 10.1016/j.ijporl.2014.10.039

Bailey, A., Luthert, P., Dean, A., Harding, B., Janota, I., Montgomery, M., et al. (1998). A clinicopathological study of autism. Brain 121, 889-905. doi: 10.1093/brain/121.5.889

Baranek, G. T. (1999). Autism during infancy: a retrospective video analysis of sensory-motor and social behaviors at 9-12 months of age. J. Autism Dev. Disord. 29, 213-224. doi: 10.1023/a:1023080005650

Bauman, M. L. (1991). Microscopic neuroanatomic abnormalities in autism. Pediatrics 87, 791-796.

Bauman, M. L. (1996). Brief report: neuroanatomic observations of the brain in pervasive developmental disorders. J. Autism Dev. Disord. 26, 199-203. doi: 10.1007/BF02172012

Bauman, M., and Kemper, T. L. (1985). Histoanatomic observations of the brain in early infantile autism. Neurology 35, 866-874. doi: 10.1212/wnl.35. 6.866

Bauman, M. L., and Kemper, T. L. (2005). Neuroanatomic observations of the brain in autism: a review and future directions. Int. J. Dev. Neurosci. 23, 183-187. doi: 10.1016/j.ijdevneu.2004.09.006

Bauman, M. L., Kemper, T. L., and Arin, D. M. (1995). Microscopic observations of the brain in Rett syndrome. Neuropediatrics 26, 105-108. doi: 10.1055/s-2007979737

Bennetto, L., Keith, J. M., Allen, P. D., and Luebke, A. E. (2017). Children with autism spectrum disorder have reduced otoacoustic emissions at the $1 \mathrm{kHz}$ mid-frequency region. Autism Res. 10, 337-345. doi: 10.1002/aur.1663

Bhat, A. N., Galloway, J. C., and Landa, R. J. (2012). Relation between early motor delay and later communication delay in infants at risk for autism. Infant Behav. Dev. 35, 838-846. doi: 10.1016/j.infbeh.2012.07.019

Bhatara, A., Babikian, T., Laugeson, E., Tachdjian, R., and Sininger, Y. S. (2013). Impaired timing and frequency discrimination in high-functioning autism spectrum disorders. J. Autism Dev. Disord. 43, 2312-2328. doi: 10.1007/s10803013-1778-y

Bidet-Caulet, A., Latinus, M., Roux, S., Malvy, J., Bonnet-Brilhault, F., and Bruneau, N. (2017). Atypical sound discrimination in children with ASD as indicated by cortical ERPs. J. Neurodev. Disord. 9:13. doi: 10.1186/s11689-0179194-9

Bolton, P. F., Golding, J., Emond, A., and Steer, C. D. (2012). Autism spectrum disorder and autistic traits in the Avon Longitudinal Study of Parents and Children: precursors and early signs. J. Am. Acad. Child Adolesc. Psychiatry 51, 249-260. doi: 10.1016/j.jaac.2011.12.009

Caldani, S., Baghdadi, M., Moscoso, A., Acquaviva, E., Gerard, C. L., Marcelli, V., et al. (2020). Vestibular functioning in children with neurodevelopmental disorders using the functional head impulse test. Brain Sci. 10:887. doi: 10.3390/brainsci10110887

Carson, T. B., Wilkes, B. J., Patel, K., Pineda, J. L., Ko, J. H., Newell, K. M., et al. (2017). Vestibulo-ocular reflex function in children with high-functioning autism spectrum disorders. Autism Res. 10, 251-266. doi: 10.1002/aur.1642

CDC.gov. (2021). Autism Spectrum Disorder (ASD). Available online at: http://www.cdc.gov/ncbddd/autism/index.html. Accessed November 19, 2017.

Ceponiene, R., Lepistö, T., Shestakova, A., Vanhala, R., Alku, P., Näätänen, R., et al. (2003). Speech-sound-selective auditory impairment in children with autism: they can perceive but do not attend. Proc. Natl. Acad. Sci. US A 100, 5567-5572. doi: 10.1073/pnas.0835631100

Chang, M. Y., Doppee, D., Yu, F., Perez, C., Coleman, A. L., and Pineles, S. L. (2021). Prevalence of ophthalmologic diagnoses in children with autism spectrum disorder using the optum dataset: APopulation-based study. Am. J. Ophthalmol. 221, 147-153. doi: 10.1016/j.ajo.2020.08.048
Chen, J., Liang, C., Wei, Z., Cui, Z., Kong, X., Dong, C. J., et al. (2019). Atypical longitudinal development of speech-evoked auditory brainstem response in preschool children with autism spectrum disorders. Autism Res. 12, 1022-1031. doi: 10.1002/aur.2110

Ciesielski, K. T., Courchesne, E., and Elmasian, R. (1990). Effects of focused selective attention tasks on event-related potentials in autistic and normal individuals. Electroencephalogr. Clin. Neurophysiol. 75, 207-220. doi: 10.1016/0013-4694(90)90174-i

Collet, L., Roge, B., Descouens, D., Moron, P., Duverdy, F., and Urgell, H. (1993). Objective auditory dysfunction in infantile autism. Lancet 342, 923-924. doi: 10.1016/0140-6736(93)91969-s

Courchesne, E., Hesselink, J. R., Jernigan, T. L., and Yeung-Courchesne, R. (1987). Abnormal neuroanatomy in a nonretarded person with autism. Unusual findings with magnetic resonance imaging. Arch. Neurol. 44, 335-341. doi: 10.1001/archneur.1987.00520150073028

Courchesne, E., Saitoh, O., Townsend, J. P., Yeung-Courchesne, R., Press, G. A., Lincoln, A. J., et al. (1994a). Cerebellar hypoplasia and hyperplasia in infantile autism. Lancet 343, 63-64. doi: 10.1016/s0140-6736(94)90923-7

Courchesne, E., Townsend, J., and Saitoh, O. (1994b). The brain in infantile autism: posterior fossa structures are abnormal. Neurology 44, 214-223. doi: $10.1212 /$ wnl.44.2.214

Courchesne, E., Yeung-Courchesne, R., Press, G. A., Hesselink, J. R., and Jernigan, T. L. (1988). Hypoplasia of cerebellar vermal lobules VI and VII in autism. N. Engl. J. Med. 318, 1349-1354. doi: 10.1056/NEJM19880526 3182102

Danesh, A. A., and Kaf, W. A. (2012). DPOAEs and contralateral acoustic stimulation and their link to sound hypersensitivity in children with autism. Int. J. Audiol. 51, 345-352. doi: 10.3109/14992027.2011.626202

Dawson, G., Toth, K., Abbott, R., Osterling, J., Munson, J., Estes, A., et al. (2004). Early social attention impairments in autism: social orienting, joint attention and attention to distress. Dev. Psychol. 40, 271-283. doi: 10.1037/0012-1649.40. 2.271

Delgado, C. F., Simpson, E. A., Zeng, G., Delgado, R. E., and Miron, O. (2021). Newborn auditory brainstem responses in children with developmental disabilities. J. Autism Dev. Disord. doi: 10.1007/s10803-021-05126-1. [Online ahead of print].

Demopoulos, C., and Lewine, J. D. (2016). Audiometric profiles in autism spectrum disorders: does subclinical hearing loss impact communication? Autism Res. 9, 107-120. doi: 10.1002/aur.1495

ElMoazen, D., Sobhy, O., Abdou, R., and AbdelMotaleb, H. (2020). Binaural interaction component of the auditory brainstem response in children with autism spectrum disorder. Int. J. Pediatr. Otorhinolaryngol. 131:109850. doi: 10.1016/j.ijporl.2019.109850

Foss-Feig, J. H., Schauder, K. B., Key, A. P., Wallace, M. T., and Stone, W. L. (2017). Audition-specific temporal processing deficits associated with language function in children with autism spectrum disorder. Autism Res. 10, 1845-1856. doi: 10.1002/aur.1820

Furman, J. M., Osorio, M. J., and Minshew, N. J. (2015). Visual and vestibular induced eye movements in verbal children and adults with autism. Autism Res. 8, 658-667. doi: 10.1002/aur.1481

Gaffney, G. R., Kuperman, S., Tsai, L. Y., and Minchin, S. (1988). Morphological evidence of brainstem involvement in infantile autism. Biol. Psychiatry 24, 578-586. doi: 10.1016/0006-3223(88)90168-0

Gernsbacher, M. A., Sauer, E. A., Geye, H. M., Schweigert, E. K., and Goldsmith, H. (2008). Infant and toddler oral- and manual-motor skills predict later speech fluency in autism. J. Child Psychol. Psychiatry 49, 43-50. doi: 10.1111/j.14697610.2007.01820.x

Gillberg, C., Rosenhall, U., and Johansson, E. (1983). Auditory brainstem responses in childhood psychosis. J. Autism Dev. Dis. 13, 181-195. doi: $10.1007 / \mathrm{BF} 01531818$

Goldberg, M. C., Landa, R., Lasker, A., Cooper, L., and Zee, D. S. (2000) Evidence of normal cerebellar control of the vestibuloocular reflex (VOR) in children with high-functioning autism. J. Autism Dev. Disord. 30, 519-524. doi: 10.1023/a:1005631225367

Gomes, E., Pedroso, F. S., and Wagner, M. B. (2008). Auditory hypersensitivity in the autistic spectrum disorder. Pro Fono 20, 279-284. doi: 10.1590/s010456872008000400013 
Gravel, J. S., Dunn, M., Lee, W. W., and Ellis, M. A. (2006). Peripheral audition of children on the autistic spectrum. Ear Hear. 27, 299-312. doi: 10.1097/01.aud. 0000215979.65645.22

Greenspan, S. I., and Wieder, S. (1997). Developmental patterns and outcomes in infants and children with disorders in relating and communicating: a chart review of 200 cases of children with autistic spectrum diagnoses. J. Dev. Learn. Dis. $1,87-141$

Grewe, T. S., Danhauer, J. L., Danhauer, K. J., and Thornton, A. R. (1994). Clinical use of otoacoustic emissions in children with autism. Int. J. Pediatr. Otorhinolaryngol. 30,123-132. doi: 10.1016/0165-5876(94)90195-3

Hashimoto, T., Tayama, M., Miyazaki, M., Murakawa, K., Shimakawa, S., Yoneda, Y., et al. (1993). Brainstem involvement in high functioning autistic children. Acta Neurol Scand. 88, 123-128. doi: 10.1111/j.1600-0404.1993. tb04203.x

Hashimoto, T., Tayama, M., Miyazaki, M., Sakurama, N., Yoshimoto, T., Murakawa, K., et al. (1992). Reduced brainstem size in children with autism. Brain Dev. 14, 94-97. doi: 10.1016/s0387-7604(12)80093-3

Hashimoto, T., Tayama, M., Murakawa, K., Yoshimoto, T., Miyazaki, M., Harada, M., et al. (1995). Development of the brainstem and cerebellum in autistic patients. J. Autism Dev. Disord. 25, 1-18. doi: 10.1007/BF02178163

Hayes, R. W., and Gordon, A. G. (1977). Auditory abnormalities in autistic children. Lancet 2:767. doi: 10.1016/s0140-6736(77)90278-1

Heath, R. G. (1973). Fastigial nucleus connections to the septal region in monkey and cat: a demonstration with evoked potentials of a bilateral pathway. Biol. Psychiatry 6, 193-196.

Heath, R. G., and Harper, J. W. (1974). Ascending projections of the cerebellar fastigial nucleus to the hippocampus, amygdala and other temporal lobe sites: evoked potential and histological studies in monkeys and cats. Exp. Neurol. 45, 268-287. doi: 10.1016/0014-4886(74)90118-6

Hermelin, B., and Frith, U. (1971). Psychological studies of childhood autism: can autistic children make sense of what they see and hear?. J. Special Edu. 5, $107-117$.

Jayanath, S., and Ozonoff, S. (2020). First parental concerns and age at diagnosis of autism spectrum disorder: a retrospective review from malaysia. Malays. J. Med. Sci. 27, 78-89. doi: 10.21315/mjms2020.27.5.8

Jeste, S. S., and Nelson, C. A., 3rd (2009). Event related potentials in the understanding of autism spectrum disorders: an analytical review. J. Autism Dev. Disord. 39, 495-510. doi: 10.1007/s10803-008-0652-9

Källstrand, J., Olsson, O., Nehlstedt, S. F., Sköld, M. L., and Nielzén, S. (2010). Abnormal auditory forward masking pattern in the brainstem response of individuals with Asperger syndrome. Neuropsychiatr. Dis. Treat. 6, 289-296. doi: $10.2147 /$ ndt.s10593

Kanner, L. (1943). Autistic disturbances of affective contact. Nervous Child 2, 217-250.

Khalfa, S., Bruneau, N., Rogé, B., Georgieff, N., Veuillet, E., Adrien, J. L., et al. (2001). Peripheral auditory asymmetry in infantile autism. Eur. J. Neurosci. 13, 628-632. doi: 10.1046/j.1460-9568.2001.01423.x

Khalfa, S., Bruneau, N., Rogé, B., Georgieff, N., Veuillet, E., Adrien, J. L., et al. (2004). Increased perception of loudness in autism. Hear Res. 198, 87-92. doi: 10.1016/j.heares.2004.07.006

Kleiman, M. D., Neff, S., and Rosman, N. P. (1992). The brain in infantile autism: are posterior fossa structures abnormal? Neurology 42, 753-760. doi: 10.1212/wnl.42.4.753

Klin, A. (1991). Young autistic children's listening preferences in regard to speech: a possible characterization of the symptom of social withdrawal. J. Autism Dev. Disord. 21, 29-42. doi: 10.1007/BF02206995

Klin, A. (1993). Auditory brainstem responses in autism: brainstem dysfunction or peripheral hearing loss? J. Autism Dev. Disord. 23, 15-35. doi: 10.1007/BF01066416

Koegel, R. L., and Schreibman, L. (1976). Identification of consistent responding to auditory stimuli by a functionally "deaf" autistic child. J. Autism Child. Schizophr. 6, 147-156. doi: 10.1007/BF01538058

Kulesza, R. J., Jr (2007). Cytoarchitecture of the human superior olivary complex: medial and lateral superior olive. Hear Res. 225, 80-90. doi: 10.1016/j.heares. 2006.12.006

Kulesza, R. J., Jr, Lukose, R., and Stevens, L. V. (2011). Malformation of the human superior olive in autistic spectrum disorders. Brain Res. 1367, 360-371. doi: 10.1016/j.brainres.2010.10.015
Kulesza, R. J., and Mangunay, K. (2008). Morphological features of the medial superior olive in autism. Brain Res. 1200, 132-137. doi: 10.1016/j.brainres.2008. 01.009

Kwon, S., Kim, J., Choe, B. H., Ko, C., and Park, S. (2007). Electrophysiologic assessment of central auditory processing by auditory brainstem responses in children with autism spectrum disorders. J. Korean Med. Sci. 22, 656-659. doi: $10.3346 / \mathrm{jkms} .2007 .22 .4 .656$

Lai, M.-C., Lombardo, M. V., and Baron-Cohen, S. (2014). Autism. Lancet 383, 896-910. doi: 10.1016/S0140-6736(13)61539-1

Levitt, J. G., Blanton, R., Capetillo-Cunliffe, L., Guthrie, D., Toga, A., and McCracken, J. T. (1999). Cerebellar vermis lobules VIII-X in autism. Prog. Neuropsychopharmacol. Biol. Psychiatry 23, 625-633. doi: 10.1016/s02785846(99)00021-4

Li, B., Bos, M. G., Stockmann, L., and Rieffe, C. (2020). Emotional functioning and the development of internalizing and externalizing problems in young boys with and without autism spectrum disorder. Autism 24, 200-210. doi: 10.1177/1362361319874644

Linke, A. C., Jao Keehn, R. J., Pueschel, E. B., Fishman, I., and Müller, R. A. (2018). Children with ASD show links between aberrant sound processing, social symptoms and atypical auditory interhemispheric and thalamocortical functional connectivity. Dev. Cogn. Neurosci. 29, 117-126. doi: 10.1016/j.dcn. 2017.01.007

Lodhia, V., Brock, J., Johnson, B. W., and Hautus, M. J. (2014). Reduced object related negativity response indicates impaired auditory scene analysis in adults with autistic spectrum disorder. PeerJ. 2:e261. doi: 10.7717/peerj.261

Lodhia, V., Hautus, M. J., Johnson, B. W., and Brock, J. (2018). Atypical brain responses to auditory spatial cues in adults with autism spectrum disorder. Eur. J. Neurosci. 47, 682-689. doi: 10.1111/ejn.13694

Lukose, R., Beebe, K., and Kulesza, R. J. (2015). Organization of the human superior olivary complex in $15 \mathrm{q}$ duplication syndromes and autism spectrum disorders. Neuroscience 286, 216-230. doi: 10.1016/j.neuroscience.2014. 11.033

Lukose, R., Brown, K., Barber, C. M., and Kulesza, R. J. (2013). Quantification of the stapedial reflex reveals delayed responses in autism. Autism Res. 6, 344-353. doi: 10.1002/aur.1297

Lukose, R., Schmidt, E., Wolski, T. P., Jr, Murawski, N. J., and Kulesza, R. J., Jr (2011). Malformation of the superior olivary complex in an animal model of autism. Brain Res. 1398, 102-112. doi: 10.1016/j.brainres.2011.05.013

Lysakowski, A., and Goldeberg, J. M. (2004). "Morphophysiology of theh vestibular periphery," in The Vestibular System, eds S. M. Highstein, R. R. Fay and A. N. Popper (New York: Springer).

Mansour, Y., and Kulesza, R. (2020). Three dimensional reconstructions of the superior olivary complex from children with autism spectrum disorder. Hear Res. 393:107974. doi: 10.1016/j.heares.2020.107974

Mansour, Y., and Kulesza, R. (2021). Distribution of glutamatergic and glycinergic inputs onto human auditory coincidence detector neurons. Neuroscience 468, 75-87. doi: 10.1016/j.neuroscience.2021.06.004

Martineau, J., Garreau, B., Roux, S., and Lelord, G. (1987). Auditory evoked responses and their modifications during conditioning paradigm in autistic children. J. Autism Dev. Disord. 17, 525-539. doi: 10.1007/BF01486968

Martineau, J., Roux, S., Adrien, J. L., Garreau, B., Barthélémy, C., and Lelord, G. (1992). Electrophysiological evidence of different abilities to form crossmodal associations in children with autistic behavior. Electroencephalogr. Clin. Neurophysiol. 82, 60-66. doi: 10.1016/0013-4694(92)90183-i

Maziade, M., Mérette, C., Cayer, M., Roy, M. A., Szatmari, P., Côté, R., et al. (2000). Prolongation of brainstem auditory-evoked responses in autistic probands and their unaffected relatives. Arch. Gen. Psychiatry 57, 1077-1083. doi: 10.1001/archpsyc.57.11.1077

Miron, O., Ari-Even Roth, D., Gabis, L. V., Henkin, Y., Shefer, S., Dinstein, I., et al. (2016). Prolonged auditory brainstem responses in infants with autism. Autism Res. 9, 689-695. doi: 10.1002/aur.1561

Miron, O., Beam, A. L., and Kohane, I. S. (2018). Auditory brainstem response in infants and children with autism spectrum disorder: a meta-analysis of wave, V. Autism Res. 11, 355-363. doi: 10.1002/aur.1886

Miron, O., Delgado, R. E., Delgado, C. F., Simpson, E. A., Yu, K. H., Gutierrez, A., et al. (2021). Prolonged auditory brainstem response in universal hearing screening of newborns with autism spectrum disorder. Autism Res. 14, 46-52. doi: 10.1002/aur.2422 
Molloy, C. A., Dietrich, K. N., and Bhattacharya, A. (2003). Postural stability in children with autism spectrum disorder. J. Autism Dev. Disord. 33, 643-652. doi: 10.1023/b:jadd.0000006001.00667.4c

Murakami, J. W., Courchesne, E., Press, G. A., Yeung-Courchesne, R., and Hesselink, J. R. (1989). Reduced cerebellar hemisphere size and its relationship to vermal hypoplasia in autism. Arch. Neurol. 46, 689-694. doi: 10.1001/archneur.1989.00520420111032

O'Connor, K. (2012). Auditory processing in autism spectrum disorder: a review. Neurosci. Biobehav. Rev. 36, 836-854. doi: 10.1016/j.neubiorev.2011.11.008

Ogawa, T. (1989). [Neurophysiological study of autistic children]. No To Hattatsu $21,163-169$

Orekhova, E. V., Tsetlin, M. M., Butorina, A. V., Novikova, S. I., Gratchev, V. V., Sokolov, P. A., et al. (2012). Auditory cortex responses to clicks and sensory modulation difficulties in children with autism spectrum disorders (ASD). PLoS One 7:e39906. doi: 10.1371/journal.pone.0039906

Ornitz, E. M. (1969). Disorders of perception common to early infantile autism and schizophrenia. Compr. Psychiatry 10, 259-274. doi: 10.1016/0010$440 x(69) 90002-9$

Ornitz, E. M. (1970). Vestibular dysfunction in schizophrenia and childhood autism. Compr. Psychiatry 11, 159-173. doi: 10.1016/0010-440x(70)90157-4

Ornitz, E. M., Atwell, C. W., Kaplan, A. R., and Westlake, J. R. (1985). Brain-stem dysfunction in autism. Results of vestibular stimulation. Arch. Gen. Psychiatry 42, 1018-1025. doi: 10.1001/archpsyc.1985.01790330102012

Ornitz, E. M., Ritvo, E. R., Panman, L. M., Lee, Y. H., Carr, E. M., and Walter, R. D. (1968). The auditory evoked response in normal and autistic children during sleep. Electroencephalogr. Clin. Neurophysiol. 25, 221-230. doi: 10.1016/00134694(68)90019-9

Ornitz, E. M., Tanguay, P. E., Lee, J. C., Ritvo, E. R., Sivertsen, B., and Wilson, C. (1972). The effect of stimulus interval on the auditory evoked response during sleep in autistic children. J. Autism Child. Schizophr. 2, 140-150. doi: 10.1007/BF01537567

Osterling, J., and Dawson, G. J. (1994). Early recognition of children with autism: a study of first birthday home videotapes. Autism Dev. Disord. 24, 247-257. doi: 10.1007/BF02172225

Pineda, R., Melchior, K., Oberle, S., Inder, T., and Rogers, C. (2015). Assessment of autism symptoms during the neonatal period: is there early evidence of autism risk?. Am. J. Occup. Ther. 69, 6904220010p1-6904220010p11. doi: 10.5014/ajot. 2015.015925

Piven, J., Nehme, E., Simon, J., Barta, P., Pearlson, G., and Folstein, S. E. (1992). Magnetic resonance imaging in autism: measurement of the cerebellum, pons and fourth ventricle. Biol. Psychiatry 31, 491-504. doi: 10.1016/00063223(92)90260-7

Ramezani, M., Lotfi, Y., Moossavi, A., and Bakhshi, E. (2019). Auditory brainstem response to speech in children with high functional autism spectrum disorder. Neurol. Sci. 40, 121-125. doi: 10.1007/s10072-018-3594-9

Reynolds, B. S., Newsom, C. D., and Lovaas, O. I. (1974). Auditory overselectivity in autistic children. J. Abnorm. Child Psychol. 2, 253-263. doi: 10.1007/BF00919253

Ritvo, E. R., Freeman, B. J., Scheibel, A. B., Duong, T., Robinson, H., Guthrie, D., et al. (1986). Lower purkinje cell counts in the cerebella of four autistic subjects: initial findings of the UCLA-NSAC autopsy research report. Am. J. Psychiatry 143, 862-866. doi: 10.1176/ajp.143.7.862

Ritvo, E. R., Ornitz, E. M., Eviatar, A., Markham, C. H., Brown, M. B., and Mason, A. (1969). Decreased postrotatory nystagmus in early infantile autism. Neurology 19, 653-658. doi: 10.1212/wnl.19.7.653

Rodier, P. M., Ingram, J. L., Tisdale, B., Nelson, S., and Romano, J. (1996). Embryological origin for autism: developmental anomalies of the cranial nerve motor nuclei. J. Comp. Neurol. 370, 247-261. doi: 10.1002/(SICI)10969861(19960624)370:2<247::AID-CNE8 >3.0.CO;2-2

Roper, L., Arnold, P., and Monteiro, B. (2003). Co-occurrence of autism and deafness: diagnostic considerations. Autism 7, 245-253. doi: 10.1177/1362361303007003002

Rosenblum, S. M., Arick, J. R., Krug, D. A., Stubbs, E. G., Young, N. B., and Pelson, R. O. (1980). Auditory brainstem evoked responses in autistic children. J. Autism Dev. Disord. 10, 215-225. doi: 10.1186/s13195-020-00654-x.

Rosenhall, U., Nordin, V., Sandström, M., Ahlsén, G., and Gillberg, C. (1999). Autism and hearing loss. J. Autism Dev. Disord. 29, 349-357. doi: 10.1023/a:1023022709710
Roth, D. A., Muchnik, C., Shabtai, E., Hildesheimer, M., and Henkin, Y. (2012). Evidence for atypical auditory brainstem responses in young children with suspected autism spectrum disorders. Dev. Med. Child Neurol. 54, 23-29. doi: $10.1111 / j .1469-8749.2011 .04149 . x$

Russo, N., Nicol, T., Trommer, B., Zecker, S., and Kraus, N. (2009). Brainstem transcription of speech is disrupted in children with autism spectrum disorders. Dev. Sci. 12, 557-567. doi: 10.1111/j.1467-7687.2008.00790.x

Russo, N. M., Skoe, E., Trommer, B., Nicol, T., Zecker, S., Bradlow, A., et al. (2008). Deficient brainstem encoding of pitch in children with Autism Spectrum Disorders. Clin. Neurophysiol. 119, 1720-1731. doi: 10.1016/j.clinph.2008. 01.108

Sacrey, L.-A. R., Germani, T., Bryson, S. E., and Zwaigenbaum, L. (2014). Reaching and grasping in autism spectrum disorder: a review of recent literature. Front. Neurol. 5:6. doi: 10.3389/fneur.2014.00006

Schofield, B. R. (2010). "Structural organization of the descending auditory pathway," in The Oxford Handbook of Auditory Science: Auditory Brain., eds A. Rees and A. R. Palmer (New York, NY: Oxford University Press), 42-64.

Scott, J. A., Schumann, C. M., Goodlin-Jones, B. L., and Amaral, D. G. (2009). A comprehensive volumetric analysis of the cerebellum in children and adolescents with autism spectrum disorder. Autism Res. 2, 246-257. doi: $10.1002 /$ aur. 97

Sersen, E. A., Heaney, G., Clausen, J., Belser, R., and Rainbow, S. (1990). Brainstem auditory-evoked responses with and without sedation in autism and Down's syndrome. Biol. Psychiatry 27, 834-840. doi: 10.1016/0006-3223(90) 90464-d

Slavik, B., Kitsuwa-Lowe, J., Danner, P., Green, J., and Ayres, A. (1984). Vestibular stimulation and eye contact in autistic children. Neuropediatrics 15, 33-36. doi: 10.1055/s-2008-1052337

Smith, D. E., Miller, S. D., Stewart, M., Walter, T. L., and McConnell, J. V. (1988). Conductive hearing loss in autistic, learning-disabled and normal children. J. Autism Dev. Disord. 18, 53-65. doi: 10.1007/BF022 11818

Smoot Reinert, S., Jackson, K., and Bigelow, K. (2015). Using posturography to examine the immediate effects of vestibular therapy for children with autism spectrum disorders: a feasibility study. Phys. Occup. Ther. Pediatr. 35, 365-380. doi: 10.3109/01942638.2014.975313

Sohmer, H. (1982). Auditory nerve-brain stem responses (ABR) in children with developmental brain disorders and in high risk neonates. Electroencephalogr. Clin. Neurophysiol. Suppl. 36, 315-327.

Student, M., and Sohmer, H. (1978). Evidence from auditory nerve and brainstem evoked responses for an organic brain lesion in children with autistic traits. J. Autism Child. Schizophr. 8, 13-20. doi: 10.1007/BF01550274

Szelag, E., Kowalska, J., Galkowski, T., and Pöppel, E. (2004). Temporal processing deficits in high-functioning children with autism. Br. J. Psychol. 95, 269-282. doi: 10.1348/0007126041528167

Talge, N. M., Tudor, B. M., and Kileny, P. R. (2018). Click-evoked auditory brainstem responses and autism spectrum disorder: a meta-analytic review. Autism Res. 11, 916-927. doi: 10.1002/aur.1946

Tanguay, P. E., Edwards, R. M., Buchwald, J., Schwafel, J., and Allen, V. (1982). Auditory brainstem evoked responses in autistic children. Arch. Gen. Psychiatry 39, 174-180. doi: 10.1001/archpsyc. 1982.04290020040008

Taș, M., Yilmaz, Ş., Bulut, E., Polat, Z., and Taş, A. (2017). Otoacoustic emissions in young children with autism. J. Int. Adv. Otol. 13, 327-332. doi: 10.5152/iao. 2017.3105

Taylor, M. J., Rosenblatt, B., and Linschoten, L. (1982). Auditory brainstem response abnormalities in autistic children. Can. J. Neurol. Sci. 9, 429-433. doi: $10.1017 / \mathrm{s} 0317167100044346$

Teder-Sälejärvi, W. A., Pierce, K. L., Courchesne, E., and Hillyard, S. A. (2005). Auditory spatial localization and attention deficits in autistic adults. Brain Res. Cogn. Brain Res. 23, 221-234. doi: 10.1016/j.cogbrainres.2004. 10.021

Thabet, E. M. (2014). Ocular vestibular evoked myogenic potentials n10 response in autism spectrum disorders children with auditory hypersensitivity: an indicator of semicircular canal dehiscence. Eur. Arch. Otorhinolaryngol. 271, 1283-1288. doi: 10.1007/s00405-013-2736-1

Tharpe, A. M., Bess, F. H., Sladen, D. P., Schissel, H., Couch, S., and Schery, T. (2006). Auditory characteristics of children with autism. Ear Hear. 27, 430-441. doi: 10.1097/01.aud.0000224981.60575.d8 
Thivierge, J., Bédard, C., Côté, R., and Maziade, M. (1990). Brainstem auditory evoked response and subcortical abnormalities in autism. Am. J. Psychiatry 147, 1609-1613. doi: 10.1176/ajp.147.12.1609

Tomchek, S. D., and Dunn, W. (2007). Sensory processing in children with and without autism: a comparative study using the short sensory profile. Am. J. Occup. Ther. 61, 190-200. doi: 10.5014/ajot.61.2.190

Tu, S., Mason, C., Rooks-Ellis, D. L., and Lech, P. (2020). Odds of autism at 5 to 10 years of age for children who did not pass their automated auditory brainstem response newborn hearing screen, but were diagnosed with normal hearing. J. Early Hear. Detect. Interv. 5, 1-12. doi: 10.26077/cp8w9r69

Van Hecke, R., Danneels, M., Dhooge, I., Van Waelvelde, H., Wiersema, J. R., Deconinck, F. J. A., et al. (2019). Vestibular function in children with neurodevelopmental disorders: a systematic review. J. Autism Dev. Disord. 49, 3328-3350. doi: 10.1007/s10803-019-04059-0

Warr, W. B. (1975). Olivocochlear and vestibular efferent neurons of the feline brain stem: their location, morphology and number determined by retrograde axonal transport and acetylcholinesterase histochemistry. J. Comp. Neurol. 161, 159-181. doi: 10.1002/cne.9016 10203

Wegiel, J., Flory, M., Kuchna, I., Nowicki, K., Ma, S. Y., Imaki, H., et al. (2014). Brainregion-specific alterations of the trajectories of neuronal volume growth throughout the lifespan in autism. Acta Neuropathol. Commun. 2:28. doi: 10.1186/2051-5960-2-28

Wegiel, J., Kuchna, I., Nowicki, K., Imaki, H., Wegiel, J., Marchi, E., et al. (2010). The neuropathology of autism: defects of neurogenesis and neuronal migration and dysplastic changes. Acta Neuropathol. 119, 755-770. doi: 10.1007/s00401010-0655-4

Werner, E., Dawson, G., Osterling, J., and Dinno, N. (2000). Brief report: recognition of autism spectrum disorder before one year of age: a retrospective study based on home videotapes. J. Autism Dev. Disord. 30, 157-162. doi: 10.1023/a:1005463707029

Williams, R. S., Hauser, S. L., Purpura, D. P., DeLong, G. R., and Swisher, C. N. (1980). Autism and mental retardation: neuropathologic studies performed in four retarded persons with autistic behavior. Arch. Neurol. 37, 749-753. doi: 10.1001/archneur.1980.00500610029003

Wong, V. C., and Kwan, Q. K. (2010). Randomized controlled trial for early intervention for autism: a pilot study of the Autism 1-2-3 Project. J. Autism Dev. Disord. 40, 677-688. doi: 10.1007/s10803-009-0916-z

Wong, V., and Wong, S. N. (1991). Brainstem auditory evoked potential study in children with autistic disorder. J. Autism Dev. Disord. 21, 329-340. doi: 10.1007/BF02207329

Conflict of Interest: The authors declare that the research was conducted in the absence of any commercial or financial relationships that could be construed as a potential conflict of interest.

Publisher's Note: All claims expressed in this article are solely those of the authors and do not necessarily represent those of their affiliated organizations, or those of the publisher, the editors and the reviewers. Any product that may be evaluated in this article, or claim that may be made by its manufacturer, is not guaranteed or endorsed by the publisher.

Copyright (C) 2021 Mansour, Burchell and Kulesza. This is an open-access article distributed under the terms of the Creative Commons Attribution License (CC BY). The use, distribution or reproduction in other forums is permitted, provided the original author(s) and the copyright owner(s) are credited and that the original publication in this journal is cited, in accordance with accepted academic practice. No use, distribution or reproduction is permitted which does not comply with these terms. 